\title{
COMPARISON OF SOLIFENACIN VERSUS COMBINATION OF SOLIFENACIN AND TAMSULOSIN IN IMPROVING UNILATERAL DOUBLE-J STENT RELATED LOWER URINARY TRACT SYMPTOMS
}

\author{
Muhammad Tanveer Sajid, Sami Ur Rehman, Muhammad Akmal, Hussain Ahmad, Zahoor Iqbal Mirza, \\ Arshad Mahmood \\ Armed Forces Institute of Urology/National University of Medical Sciences (NUMS) Rawalpindi Pakistan
}

\begin{abstract}
Objective: To compare Solifenacin versus solifenacin plus tamsulosin in terms of international prostate symptom score (IPSS) for lower urinary tract symptoms (LUTS) in patients with unilateral double-J (DJ) ureteric stents.

Study Design: Comparative cross sectional study.

Place and Duration of Study: Armed Forces Institute of Urology, Rawalpindi from Sep 2018 to Feb 2019.

Methodology: A total of two hundred $(n=200)$ patients of either gender aged 20-50 years, who underwent unilateral DJ stenting for different endourological procedures, were enrolled after satisfying inclusion/exclusion criteria and then randomly allocated to group A (Solifenacin $5 \mathrm{mg}$ once daily (OD) \pm placebo for 2 weeks) or group B (Solifenacin $5 \mathrm{mg}$ OD \pm Tamsulosin $0.4 \mathrm{mg}$ OD for 2 weeks) respectively. Baseline (1st post-operative day) and Post 02 weeks treatment IPSS was recorded and analyzed.

Results: Mean age of presentation in group A and group B was $41.11 \pm 6.45$ vs $39.86 \pm 5.34$ years with $p$-value 0.14 . Majority of patients in both groups were male (34\% female in group A while $31 \%$ in group B, difference being statistically insignificant $p$ 0.65). Baseline IPSS in group A and group B was $10.33 \pm 2.72$ vs $10.46 \pm 3.12$ with $p$ value 0.76 (statistically insignificant) while post 02 weeks treatment IPSS in group A and B was $9.20 \pm 2.67$ vs 7.88 \pm 2.63 respectively with $p$-value $<0.001$, the difference being statistically significant.

Conclusions: Current study revealed significant advantage of combination therapy (solifenacin \pm tamsulosin) compared with solifenacin monotherapy in lowering LUTS based on IPSS in patients having unilateral DJ stent.
\end{abstract}

Keywords: Lower urinary tract symptoms, Solifenacin, Tamsulosin, Ureteral calculi, Ureteroscopy.

This is an Open Access article distributed under the terms of the Creative Commons Attribution License (http://creativecommons.org/licenses/by/4.0), which permits unrestricted use, distribution, and reproduction in any medium, provided the original work is properly cited.

\section{INTRODUCTION}

Ureteral stent placement is a routine urological procedure performed post ureteroscopy for various etiologies ${ }^{1}$, helping assist passage of ureteral stone, reduction in renal pelvic pressure after pyeloplasty or pyleo-or nephrolithotomy, relieving obstruction, acceleration of ureteric injury recovery and auxiliary for shockwave lithotripsy ${ }^{2}$. Procedure introduced almost five decades ago by Zimskind et als, was popularized by Finney et al, in 1978, currently being one of the most commonly carried endourological intervention worldwide ${ }^{4}$.

Despite usefulness, stent related symptoms (SRS) are cause of well documented significant morbidity with estimated incidence of $19-76 \%$.

Correspondence: Dr Muhammad Tanveer Sajid, Assistant Professor, Armed Forces Institute of Urology, Rawalpindi Pakistan Received: 23 Mar 2019; revised received: 01 Dec 2019; accepted: 03 Dec 2019
The reported bothersome urinary morbidities encountered are voiding / storage symptoms (LUTS), flank or suprapubic pain, hematuria and urinary tract infection (UTI) obviously affecting general health and work performance in as many as $80 \%$ cases $^{5}$.

Various theories have been proposed although exact pathophysiology of SRS remains unclear $^{6}$. Spasm of ureteral smooth muscle secondary to foreign body in situ, irritation of trigone by intravesical lower coil leading to bladder spasm and increase retrograde pressure transmission during voiding are few such proposed mechanisms augmented by nature of material and size of the stent ${ }^{7}$.

Tamsulosin, a selective inhibitor of a 1A/1Dadrenoceptors expressed amongst smooth muscles of ureter, trigone, prostate and bladder neck, relaxes these smooth muscles leading to reduced 
bladder outlet resistance and voiding pressure thus effectively decreasing incidence of dysuria, frequency, and pain compared to placebo $^{8}$. Solifenacin inhibits acetylcholine binding on all five subtypes of G-protein-coupled muscarinic receptors, M2/3 being most frequently found detrusor smooth muscle, interstitial and nerve cells of bladder, effectively reducing spontaneous myocyte activity leading to decreased frequency as well as intensity of bladder contractions. Solifenacin $5 \mathrm{mg}$ OD was selected due to least adverse events in clinical practice, tolerability and good efficacy 9 . IPSS is aself-administered validated psychometric tool allowing objective assessment of LUTS. Questionnaire allows quantification of the symptoms and has been validated by numerous researchers in different languages ${ }^{10}$.

Several treatment strategies have been proposed to deal with SRS. Oral NSAIDS or opioids were commonly prescribed with moderate efficacy. Alpha-1 adrenergic blockers and antimuscarinic agents have revolutionized pharmacologic management of these symptoms. However international literature review revealed inconsistent, fluctuating results and to our knowledge very limited local data was found addressing this aspect ${ }^{11}$. We aimed to evaluate whether combination of tamsulosin and solifenacin is more effective in reducing symptoms associated with indwelling double-J ureteral stents in our target population.

\section{METHODOLOGY}

This comparative cross sectional study was conducted at Armed Forces Institute of Urology, Rawalpindi from September 2018 to February 2019. The study protocol was approved by the hospital ethics review Committee (certificate no Uro-06/ERC-104585/TRG/19). Non probability consecutive sampling technique utilized at outpatient department to enroll 100 patients in each group (WHO calculator, confidence interval 95\%, power of test $80 \%$, mean IPSS population A 11.04 \& B 7.16) ${ }^{12}$, after satisfying inclusion criteria (unilateral DJ stenting, age 20-50 years \& of either gender) while patients having bleeding disorders, lactating/pregnant, bilateral ureteric stents, anticholinergics or a-blockers use in past, bladder outlet obstruction or prostatitis were excluded. Randomization into two groups was done by computer generated random number table and written informed consent was obtained. Both investigators and patients were blinded to the randomization scheme and medications. Sequentially numbered containers having solifenacin \pm placebo or solifenacin \pm Tamsulosin were administered by duty nurse knowing allocation sequence and patient grouping.

Demographic information including name, age and gender were taken from all patients. Preoperative assessment included routine investigations for the planned procedures to be carried out under general or regional anesthesia. A Soft Percuflex $^{\mathrm{TM}}$ Stent with Hydro Plus ${ }^{\mathrm{TM}}$ (Contour $^{\mathrm{TM}}$ Ureteral Stent, Boston Scientific Corporation, Natick, MA 01760-1537, USA) was used, adjusting the length and caliber for each patient. Procedure was performed by two consultant urologists without knowing group of the patient to eliminate bias. A plain radiograph of the kidneys, ureters and bladder confirmed the position of the DJ stent in all patients before discharge. Patients in group A and B received Solifenacin $(5 \mathrm{mg}) \pm$ placebo and Solifenacin $(5 \mathrm{mg}) \pm$ Tamsulosin $(0.4$ $\mathrm{mg}$ ) OD respectively for 2 weeks. IPSS was recorded at 1 st post-operative day and after 2 weeks on a pre-designed proforma.

Statistical analysis was done using SPSS-24. Descriptive statistics were used to calculate means \pm standard deviation for quantitative variables. Frequencies with percentage were calculated for qualitative variables. Independent sample t-test was applied to compare mean of IPSS after 14 days in both groups. Post stratification t-test was applied. $p$-value $\leq 0.05$ was considered significant.

\section{RESULTS}

A total of two hundred patients were enrolled and randomly allocated. Baseline characteristics were similar in both groups. Mean age of presentation in group A and group B was $41.11 \pm$ 
6.45 vs $39.86 \pm 5.34$ years with $p$-value 0.14 . Majority of patients in both groups were male (34 $(34 \%)$ female in group A while $31(31 \%)$ in group

Table-I: Demographic variables of the patients included in the study $(n=200)$.

\begin{tabular}{|c|c|c|c|}
\hline $\begin{array}{l}\text { Demographic } \\
\text { Variable }\end{array}$ & $\begin{array}{c}\text { Group A } \\
(\mathrm{n}=100) \\
\text { (Solifenacin) }\end{array}$ & $\begin{array}{c}\begin{array}{c}\text { Group B } \\
(n=100) \\
(\text { Solifenacin } \pm \\
\text { Tamsulosin) }\end{array} \\
\end{array}$ & $\begin{array}{c}p \text { - } \\
\text { value }\end{array}$ \\
\hline \multicolumn{4}{|l|}{ Age (years) } \\
\hline Mean \pm SD & $41.11 \pm 6.45$ & $39.86 \pm 5.34$ & 0.14 \\
\hline \multicolumn{4}{|l|}{ Gender Ratio } \\
\hline $\mathrm{M}: \mathrm{F}$ & $1.9: 1$ & $2.2: 1$ & \multirow{3}{*}{0.65} \\
\hline Male & $66(66 \%)$ & $69(69 \%)$ & \\
\hline Female & $34(34 \%)$ & $31(31 \%)$ & \\
\hline \multicolumn{4}{|c|}{ Age Groups, n (\%) } \\
\hline 20-35 Years & $21(21.0 \%)$ & $25(25.0 \%)$ & \multirow{2}{*}{0.50} \\
\hline $36-50$ Years & $79(79.0 \%)$ & $75(75 \%)$ & \\
\hline \multicolumn{4}{|c|}{ Body Mass Index (BMI) } \\
\hline Mean \pm SD & $27.10 \pm 4.13$ & $27.40 \pm 3.84$ & 0.59 \\
\hline \multicolumn{4}{|l|}{ ASA Status } \\
\hline I & $51(51 \%)$ & $37(37 \%)$ & \multirow{4}{*}{0.20} \\
\hline II & $41(41 \%)$ & $49(49 \%)$ & \\
\hline III & $06(6 \%)$ & $10(10 \%)$ & \\
\hline IV & $02(2 \%)$ & $04(4 \%)$ & \\
\hline \multicolumn{4}{|c|}{ Operation Time (Minutes) } \\
\hline Mean \pm SD & $32.54 \pm 8.57$ & $32.48 \pm 7.73$ & 0.95 \\
\hline \multicolumn{4}{|c|}{$\begin{array}{l}\text { Table-II: IPSS in both groups baseline, baseline } \\
\text { stratified and at } 02 \text { weeks post treatment. }\end{array}$} \\
\hline Variable & $\begin{array}{c}\text { Group A } \\
(\mathrm{n}=100) \\
\text { (Solifenacin) }\end{array}$ & $\begin{array}{c}\text { Group B } \\
(n=100) \\
\text { (Solifenacin } \pm \\
\text { Tamsulosin) }\end{array}$ & $\begin{array}{c}p \text { - } \\
\text { value }\end{array}$ \\
\hline \multicolumn{4}{|l|}{ Baseline IPSS } \\
\hline Mean \pm SD & $10.33 \pm 2.87$ & $10.46 \pm 3.12$ & 0.76 \\
\hline \multicolumn{4}{|c|}{ Stratified Baseline IPSS, $\mathbf{n}(\%)$} \\
\hline IPSS 1-7 & $21(21 \%)$ & $20(20 \%)$ & 0861 \\
\hline IPSS 8-19 & $79(79 \%)$ & & 0.861 \\
\hline \multicolumn{4}{|c|}{ IPSS at 02 Weeks } \\
\hline Mean \pm SD & $9.20 \pm 2.67$ & $7.88 \pm 2.63$ & 0.001 \\
\hline
\end{tabular}

$\mathrm{B}$, difference being statistically insigni-ficant $p$ 0.65 ) (table-I). Baseline IPSS in group $A$ and group B was $10.33 \pm 2.72$ vs $10.46 \pm 3.12$ with $p$ value 0.76 (statistically insignificant) while post 02 weeks treatment IPSS in group A and B was $9.20 \pm 2.67$ vs $7.88 \pm 2.63$ respectively with $p$-value $<0.001$, the difference being statistically significant. Similar trend was noted when data was stratified with respect to gender, age and baseline
IPSS. $p$-value was $<0.05$ in all cases, except for younger age group where no significant difference was noted ( $p$ 0.26) (table-III).

Table-III: Data stratification of mean IPSS at 02 weeks with respect to age, gender and baseline IPSS in both groups.

\begin{tabular}{|c|c|c|c|}
\hline \multirow[b]{2}{*}{ Variable } & \multicolumn{2}{|c|}{$\begin{array}{c}\text { IPSS at } 2 \text { Weeks Post } \\
\text { Treatment }\end{array}$} & \multirow[b]{2}{*}{$\begin{array}{c}p- \\
\text { value }\end{array}$} \\
\hline & $\begin{array}{c}\text { Group A } \\
(n=100) \\
\text { (Solifenacin) } \\
\text { (Mean } \pm \text { SD) }\end{array}$ & $\begin{array}{c}\text { Group B } \\
(n=100) \\
\text { (Solifenacin } \pm \\
\text { Tamsulosin) } \\
\text { (Mean } \pm \text { SD) }\end{array}$ & \\
\hline \multicolumn{4}{|c|}{ Age Groups (Years) } \\
\hline $20-35$ & $8.95 \pm 2.38$ & $8.08 \pm 2.78$ & 0.018 \\
\hline $36-50$ & $9.27 \pm 2.75$ & $7.81 \pm 2.60$ & $<0.01$ \\
\hline \multicolumn{4}{|l|}{ Gender } \\
\hline Male & $9.14 \pm 2.65$ & $8.00 \pm 2.73$ & 0.003 \\
\hline Female & $9.32 \pm 2.74$ & $7.61 \pm 2.42$ & $<0.001$ \\
\hline \multicolumn{4}{|c|}{ Baseline IPSS } \\
\hline IPSS 1-7 & $6.62 \pm 0.87$ & $4.50 \pm 0.52$ & $<0.001$ \\
\hline IPSS 8-19 & $9.89 \pm 2.57$ & $8.73 \pm 2.24$ & $<0.01$ \\
\hline
\end{tabular}

\section{DISCUSSION}

Both a-blockers and anti-muscarinic drugs are effective for ureteral SRS whether used alone or in combination ${ }^{10}$, the combination being better option ${ }^{11,13}$. However; clinical trials have combined tamsulosin with different doses of solifenacin with conflicting results ${ }^{14,15}$. Present study was designed to compare solifenacin versus solifenacin plus tamsulosin for the management of SRS in local population. A total of two hundred $(n=200)$ patients of either gender were enrolled and randomly allocated to group A (Solifenacin) and group B (Solifenacin \pm Tamsulosin) for 2 weeks respectively to compare SRS in terms of IPSS. Our results revealed comparable baseline characteristics in both groups. Post 02 weeks treatment IPSS in group $\mathrm{A}$ and $\mathrm{B}$ was $9.20 \pm 2.67$ vs $7.88 \pm 2.63$ respectively with $p$-value $<0.001$ (students t-test), the difference being statistically significant supporting better efficacy of combination therapy.

These results are comparable to data quoted worldwide ${ }^{16,17}$. Abdelaal et al16, reported their findings in 260 patients divided into four groups (no treatment, tamsulosin alone, solifenacin alone or combination). A highly significant lower ureteral 
stent symptom questionnaire (USSQ) score were observed in combination group $(16.6 \pm 2.5$ vs $37.1 \pm 3.1$ vs $22.9 \pm 2.4$ vs $22 \pm 2.8$ respectively, $p<$ 0.001) while another trial carried out by Avila et al17, found combination of tamsulosin \pm oxybutynin to perform significantly better in terms of irritative symptoms, work performance and sexual score as compared to tamsulosin or oxybutynin alone $(15.5 \pm 5$ vs $21.5 \pm 6.27$ vs $17.8 \pm 5.5, p<$ 0.001). Similarly Lim et al12, evaluated tamsulosin, solifenacin and their combination in improving LUTSin 168 patients having indwelling ureteral stents in terms of International Prostate Symptom Score/quality of life (IPSS/QoL) and visual analogue pain scale (VAPS). They found significant different IPSS total score between groups (13.77 \pm 4.5 tamsulosin vs $11.04 \pm 5.29$ solifenacin vs 7.16 \pm 3.37 combination respectively, $p$-value $<0.001$ ) . Authors concluded that combination therapy should be strongly considered for patients who complain of SRS as proved by our study as well.

Yan et al18, in their meta-analysis involving 710 patients aimed to evaluate the efficacy of antimuscarinics alone or in combination with alphablockers for the treatment of SRS. Authors found significantly improved total IPSS, QoL, body pain and work performance score of USSQ in the combination group compared with antimuscarinics alone $(p<0.001)$. They concluded that alpha-blockers enhance efficacy of antimuscarinics leading to additive favorable effects in tackling SRS compared with antimuscarinics monotherapy.

In another meta-analysis, Zhang et al ${ }^{19}$, systematically evaluated efficacy of combination therapy for SRS in 545 patients. Their analysis revealed that compared with a-blockers, the combination group achieved significant improvements in total IPSS $(p<0.00001)$, obstructive sub score $(p<0.0001)$, irritative sub score $(p<0.00001)$ and QoL score $(p<0.001)$. Their findings strongly supported significant advantages of combination therapy based on IPSS as depicted by our study.

Dellis et al20, studied the effect of tamsulosin, solifenacin, and their combination in improving symptoms and quality of life in patients with indwelling ureteral stents in a RCT involving 260 patients. The validated USSQ was completed 1 and 4 weeks after stent insertion and 4 weeks after stent removal. Their results highlighted that patients on combination therapy expressed significantly less LUTS $(p<0.001)$, pain $(p<0.001)$ and work performance $(p<0.001)$ scores in the fourth week with stent in situ and after stent removal $(p=0.005)$. No patients had to discontinue medication due to side effects. They concluded that simple medication, such as tamsulosin and solifenacin alone or in combination, improves stent-related symptoms and has a positive impact on quality of life.

In another meta-analysis involving 1408 patients Zhou et al21, evaluated the effects of ablockers, antimuscarinics, or a combination of both in reducing ureteral SRS. They found that compared with a-blockers monotherapy, combination therapy has significant lower total IPSS $(p<0.00001)$, VAPS ( $p$-value 0.01), and QoL $(p<$ $0.00001)$. They concluded that combination therapy has significant advantages compared with a-blocker monotherapy supporting our results.

El-Nahas et $a l^{22}$. in their randomized controlled trial involving patients who underwent temporary unilateral ureteral stent for drainage of calcular upper tract obstruction aimed to compare the effectiveness of tamsulosin and solifenacin in relieving ureteral SRS. Patients in group 1 received placebo, group 2 received tamsulosin 0.4 $\mathrm{mg}$ once daily while those in group 3 received solifenacin $5 \mathrm{mg}$ once daily. They found the total USSQ scores in all domains, except sexual index, were significantly better in solifenacin than in tamsulosin group $(p<0.05$. They did not use combination therapy in their study.

Although all above mentioned literature favors our results, a meta-analysis by Wang el $a l^{23}$, revealed safety and efficacy of solifenacin in reducing SRS but no significant advantage was found over tamsulosin. In addition, combination of solifenacin and tamsulosin did not show beneficial effects over solifenacin monotherapy. However a recent RCT performed in 2018 revealed 
significant efficacy of combination therapy with silodosin and Solifenacin as compared to to monotherapy for relieving SRS with improved QoL and less requirement of analgesia supporting our findings ${ }^{24}$.

The results of present study should be interpreted with care as efficacy was measured after 2 weeks only and IPSS was used as measuring tool. Moreover, the study was carried out in a single center. There was no comparison of side effects as well as cost of the treatment. Large multicenter RCTs are required to further clarify the role of combination therapy adopting more validated $\mathrm{USSQ}^{25}$. Various aspects of drug therapy, like cost analysis, patient satisfaction and side effect profile, need to be studied to make this combination modality part of effective SRS care program.

\section{CONCLUSIONS}

Significant advantage of combination therapy of a-blocker and antimuscarinic compared with antimuscarinic mono therapy was observed in the present study in terms of improvement in mean IPSS at day 14. Further large scale RCTs adopting more validated USSQ as outcome measures are warranted to support the recommendation of combination therapy for routine clinical use.

\section{CONFLICT OF INTEREST}

This study has no conflict of interest to be declared by any author.

\section{REFRENCES}

1. Tailly T, Denstedt JD. Fundamentals of urinary tract drainage in: W Scott Mc Dougal, Alan J Wein et al ed. Campbell Walsh Urology, 11th Ed. Philadelphia PA: Elsevier, [Internet]. https:// www.slideshare.net/PrashantJrLlrmChauha/fundamentals-ofurinary-tract-drainage.

2. Varnavas M, Bolgeri M, Mukhtar S, Anson K. The role of tandem double-j ureteral stents in the management of malignant ureteral obstruction. J Endourol 2016; 30(4): 465-69.

3. Zimskind PD, Fetter TR, Wilkerson JL. Clinical use of long-term indwelling silicone rubber ureteral splints inserted cystoscopically. J Urol 1967; 97(5): 840-44.

4. Muslumanoglu AY, Fuglsig S, Frattini A. Risks and benefits of postoperative double-j stent placement after ureteroscopy: results from the Clinical Research Office of Endourological Society Ureteroscopy Global Study. J Endourol 2017; 31(5): 446-49.

5. Joshi HB, Stainthorpe A, Mac Donagh RP, Keeley FX, Timoney AG, Barry MJ. Indwelling ureteral stents: evaluation of symptoms, quality of life and utility. J Urol 2003; 169(3): 1065-69.
6. Koprowski C, Kim C, Modi PK, Elsamra SE. Ureteral stentassociated pain: A Review. J Endourol 2016; 30(7): 744-48.

7. Thomas R. Indwelling ureteral stents: Impact of material and shape on patient comfort. J Endourol 1993; 7(2): 137-40.

8. Anderson KE. Pharmacology of lower urinary tract smooth muscles and penile erectile tissues. Pharmacol Rev 1993; 45(3): 253-08.

9. Rahardjo HE, Syahputra FA, Islianti PI, Matondang FA. Efficacy of additional solifenacin succinate therapy for storage symptoms in females with uncomplicated lower urinary tract infection: the solution randomized controlled trial. Acta Med Indones 2018; 50(3): 200-07.

10. Arshad Z, Zaidi SZ, Jamshaid A. Development, validity and reliability of an URDU version of the International Prostate Symptom Score. J Pak Med Assoc 2018; 68(2): 200-02.

11. Kwon JK, Cho KS, Oh CK, Kang DH, Lee H, Ham WS, et al. The beneficial effect of alpha-blockers for ureteral stent-related discomfort: systematic review and network meta-analysis for alfuzosin versus tamsulosin versus placebo. BMC Urol 2015; 15(1): 55-58.

12. Lim KT, Kim YT, Lee TY, Park SY. Effects of tamsulosin, solifenacin, and combination therapy for the treatment of ureteral stent related discomforts. Korean J Urol 2011; 52(7): 485-88.

13. Hekal IA. Drug treatment of bothersome lower urinary tract symptoms after ureteric JJ-stent insertion: A contemporary, comparative, prospective, randomized placebo-controlled study, single-centre experience. Arab Juro 2016; 14(4): 262-68.

14. He F, Man L, Li G. Efficacy of a-blocker in improving ureteral stent-related symptoms: a meta-analysis of both direct and indirect comparison. Drug DD Ther 2016; 10(1): 1783-93.

15. Liu Q, Liao B, Zhang R, Jin T, Zhou L, Luo D, et al. Combination therapy only shows short-term superiority over monotherapy on ureteral stent-related symptoms-outcome from a randomized controlled trial. BMC Urol 2016; 16(1): 66-68.

16. Abdelaal AM, Al-Adl AM, Abdelbaki SA, Al Azab MM, Al Gamal KA. Efficacy and safety of tamsulosin oral-controlled absorption system, solifenacin, and combined therapy for the management of ureteric stent-related symptoms. Arab J Urol 2016; 14(2): 115-22.

17. Avila MM, Arteaga LG, Guzman RJ, Hugo A, Garcia M, Nava RE. Efficacy of tamsulosin, oxybutynin, and their combination in the control of double-J stent-related lower urinary tract symptoms. Int Brazil J Urol 2016; 42(3): 487-93.

18. Yan H, Wang Y, Sun R, Cui Y. The Efficacy of antimuscarinics alone or in combination with alpha-blockers for the treatment of ureteral stent-related symptoms: A Systematic Review and Meta-Analysis. Urol Int 2017; 99(1): 6-13.

19. Zhang YM, Chu P, Wang WJ. PRISMA-combined a-blockers and antimuscarinics for ureteral stent-related symptoms: A metaanalysis. Medicine (Baltimore) 2017; 96(7): e6098.

20. Dellis AE, Papatsoris AG, Keeley FX, Bamias A, Deliveliotis C, Skolarikos AA. Tamsulosin, solifenacin, and their combination for the treatment of stent-related symptoms: A Randomized Controlled Study. J Endourol 2017; 31(1): 100-09.

21. Zhou L, Cai X, Li H, Wang KJ. Effects of a-Blockers, Antimuscarinics, or combination therapy in relieving ureteral stent-related symptoms: A Meta-Analysis. J Endourol 2015; 29(6): 650-56.

22. El-Nahas AR, Tharwat M, Elsaadany M, Mosbah A, Gaballah MA. A randomized controlled trial comparing alpha blocker (tamsulosin) and anticholinergic (solifenacin) in treatment of ureteral stent-related symptoms. World J Urol 2016; 34(7): 963-68.

23. Wang J, Zhang X, Zhang T, Mu J, Bai B, Lei Y. The role of solifenacin, as monotherapy or combination with tamsulosin in ure- 
teral stent-related symptoms: a systematic review and metaanalysis.World J Urol 2017; 35(11): 1669-80.

24. Bhattar R, Tomar V. Comparison of safety and efficacy of silodosin, solifenacin, tadalafil and their combinations in the treatment of double-J stent- related lower urinary system symptoms:
A prospective randomized trial. Turk J Urol 2018; 44(3): 228-38.

25. Park HK, Paick SH, Kim HG. The impact of ureteral stent type on patient symptoms as determined by the ureteral stent symptom questionnaire: a prospective, randomized, controlled study. J Endourol 2015; 29(3): 367-71. 